\title{
Salmonella in the pork production chain and its impact on human health in the European Union
}

\author{
S. BONARDI* \\ Department of Veterinary Science, Unit of Food Inspection, University of Parma, Via del Taglio 10, 43126 \\ Parma, Italy
}

Received 10 August 2016; Final revision 19 December 2016; Accepted 1 February 2017;

first published online 28 February 2017

\section{SUMMARY}

Salmonella spp. comprise the second most common food-borne pathogens in the European Union (EU). The role of pigs as carriers of Salmonella has been intensively studied both on farm and at slaughter. Salmonella infection in pigs may cause fever, diarrhoea, prostration and mortality. However, most infected pigs remain healthy carriers, and those infected at the end of the fattening period could pose a threat to human health. Contamination of pig carcasses can occur on the slaughter line, and it is linked to cross-contamination from other carcasses and the presence of Salmonella in the environment. Therefore, Salmonella serovars present on pig carcasses can be different from those detected in the same bathes on the farm. In recent years, $S$. Typhimurium, $S$. Derby and $S$. serotype 4,[5],12:i:- (a monophasic variant of $S$. Typhimurium) have been the most common serovars to be detected in pigs in EU countries, but $S$. Rissen, $S$. Infantis, $S$. Enteritidis and $S$. Brandenburg have also been reported. In humans, several cases of salmonellosis have been linked to the consumption of raw or undercooked pork and pork products. Among the main serovars of porcine origin detected in confirmed human cases, $S$. Typhimurium, the monophasic variant $S$. 4,[5],12:i:- and $S$. Derby are certainly the most important.

Key words: Humans, pig, pig carcass, Salmonella enterica, slaughterhouse.

\section{INTRODUCTION}

Salmonella enterica is one of the most common and widely distributed food-borne pathogens in the European Union (EU) [1], and is considered one of the leading causes of gastroenteritis and bacteraemia in humans worldwide [2]. The most recent European Food Safety Authority (EFSA) and European Centre for Disease Prevention and Control (ECDC)

\footnotetext{
* Author for correspondence: S. Bonardi, Department of Veterinary Science, Unit of Food Inspection, University of Parma, Via del Taglio, 10, 43126, Parma, Italy.

(Email: silvia.bonardi@unipr.it)
}

report on zoonoses and zoonotic agents in the EU was published in 2015. This document presented the results of zoonoses monitoring activities carried out during 2014 in 32 European countries (28 member states and four non-member states). Human salmonellosis ranked second after campylobacteriosis with 88715 confirmed cases and an EU notification rate of 23.4 cases per 100000 population. After the declining trend observed in previous years, salmonellosis presented a $15 \cdot 3 \%$ increase in the notification rate in 2014, compared with 2013 (20.3 cases per 100000 population) [3].

Human salmonellosis is caused by both host-restricted (S. Typhi and $S$. Paratyphi A) and ubiquitous serovars, 
but only the former are responsible for the systemic life-threatening form of salmonellosis, referred to as typhoid fever [4]. Non-typhoid Salmonella infection is mainly characterised by gastroenteritis, with acute onset of fever, nausea, vomiting, abdominal cramps and diarrhoea; however, immunocompromised individuals may suffer from recurrent or prolonged Salmonella infections [5], whereas HIV patients and children could be affected by infections in the bloodstream, leading to death [6].

\section{SALMONELLA IN THE PORK PRODUCTION CHAIN}

\section{Salmonellosis in pigs}

Host adaptation of Salmonella serovars is of greatest importance in determining the clinical features and outcome of the infection. Apart from host-restricted serovars that are able to cause a typhoid-like disease in a single host species (e.g. $S$. Typhi and $S$. Paratyphi A in humans, and $S$. Typhisuis in pigs), other serovars, referred to as host-adapted serovars, are associated with one host species, but are also able to cause illness in other hosts (e.g. $S$. Choleraesuis in pigs and $S$. Dublin in cattle) [7]. $S$. Choleraesuis and $S$. Dublin generally cause severe systemic disease in pigs and cattle, respectively, but occasionally can be responsible for disease in other mammalian hosts, including humans [7]. In contrast, ubiquitous Salmonella serovars are the unrestricted serovars that are capable of causing systemic disease in a wide range of host animals, but more frequently cause a self-limiting gastroenteritis in a broad range of species. Examples of unrestricted serovars include $S$. Typhimurium and $S$. Enteritidis [7].

Infections with $S$. Typhisuis and $S$. Choleraesuis serovars in pigs usually result in swine paratyphoid, a severe systemic disease that is often fatal and characterised by fever, shivering, diarrhoea, respiratory distress and depression [8, 9]. Infected pigs exhibit clinical signs within $36-48 \mathrm{~h}$ after infection, and shed $S$. Choleraesuis in their faeces within $24 \mathrm{~h}$ of exposure. After experimental inoculation, shedding of the microorganism can vary between $10^{3}$ and $10^{6}$ colonyforming unit (CFU)/g of faeces. However, in natural infections, pigs might be exposed to lower levels of $S$. Choleraesuis (as low as $4 \times 10^{2} \mathrm{CFU} / \mathrm{g}$ of faeces) that can still be responsible for high morbidity and severe outbreaks of swine paratyphoid within a relatively short period. Transmission of $S$. Choleraesuis can thus be very efficient on the farm, during transport and in lairage before slaughter [9]. $S$. Choleraesuis, including variant Kunzendorf, was the predominant serovar isolated from pigs worldwide, over the past century (especially during the 1950s and 1960s). However, during the late 1990s and early 2000s, it was rarely detected in the EU countries [10, 11]. $S$. Choleraesuis var. Kunzendorf reappeared in Danish herds from 2012 to 2013, causing multiple outbreaks that were characterised by high mortality $(20-30 \%)$ among $7-50 \mathrm{~kg}$ pigs [12].

Although infections in pigs by ubiquitous Salmonella serovars could result in enteric and even fatal disease, infected animals frequently and asymptomatically carry these serovars in the tonsils, gut and gut-associated lymphoid tissue [10]. In EU countries, non-typhoidal Salmonella infections in pigs are related mostly to $S$. Typhimurium and its monophasic variant (antigenic formula 1,4,[5],12:i:-; 4,[5],12:i:-; or 4,12:i:-), $S$. Derby and $S$. Infantis [3, 13-15]. Other frequently reported serovars in pigs include Rissen, Panama, Goldcoast, Agona, Brandenburg, London, Anatum, Manhattan, Enteritidis and Bovismorbificans [3, 16, 17].

Transmission of Salmonella between pigs occurs mainly via the faecal-oral route [18], although some studies have demonstrated that the upper respiratory tract and lungs could be portals of entry as well [19]. A comparison between the prevalence of infection in pigs on the farm and in the abattoir revealed that prevalence on the farm often seems lower, partly because of the existence of latent, undetectable Salmonella carriers [20]. These latent carriers may begin to shed Salmonella only after leaving the farm, a process that might be triggered by stress factors linked to group housing, transportation and holding pens at the slaughterhouse, as the physiological changes associated with stress could promote recrudescence in latent carriers, or increase the susceptibility of non-carriers to new infections [21].

\section{Salmonella in pig farms (pre-harvest stage)}

The 'pre-harvest stage' refers to that part of the food chain that includes the holding period of pigs on the farm until their departure and loading for transportation to the slaughterhouse [22]. During this period, pigs could become infected with Salmonella and show clinical signs, or they could become asymptomatic carriers and excrete the pathogen in faeces, or harbour it in several tissues, such as the digestive tract, closely associated lymph nodes or the tonsils [23]. 
Among the clinically affected pigs, most are of the weaning or post-weaning age, and the fattening pigs (body weight from 65 to $100 \mathrm{~kg}$, and over) are generally asymptomatic carriers of unrestricted Salmonella serovars. The carrier status of pigs could be determined by the analysis of faecal cultures, obtained for example, via the collection of faeces with rectal swabs from randomly selected pigs during the fattening period [24]. The most frequently detected serovars in pigs on farms in the EU are $S$. Typhimurium monophasic variant, $S$. Typhimurium and $S$. Derby [13, 24, 25-27]. In 2014, the most common Salmonella serovars isolated from pigs in the EU were $S$. Typhimurium (50.3\%), $S$. Derby $(17 \cdot 5 \%), S$. enterica 1, 4,[5],12:i:- (8.4\%), $S$. Typhimurium var. Copenhagen $(4 \cdot 4 \%), S$. London $(2 \cdot 1 \%), S$. Infantis $(1 \cdot 7 \%), S$. Muenchen $(1 \cdot 6 \%), S$. Rissen $(1 \cdot 5 \%)$, and $S$. Livingstone $(1 \cdot 2 \%)$ [3]. $S$. Typhimurium has been the predominant serotype detected within the last few years, accounting for as much as $72.8 \%$ of isolates in 2012. Since $S$. Typhimurium had been reported in 9 out of 10 member states in 2014, and was commonly reported in the baseline surveys of slaughter pigs and breeding pigs in 2006/2007 and 2009, respectively, its distribution across the EU can be assumed to be relatively wide $[28,29]$. The prevalence of isolates of monophasic strains of $S$. Typhimurium has shown no considerable change over the last few years, ranging between $8 \cdot 4 \%$ of all isolates in 2014, and $14 \%$ in 2013. Within recent years, Poland, Malta, the UK and Italy accounted for a large proportion of pig isolates of the monophasic $S$. Typhimurium (reported antigenic formulae 1,4,5,12:i:- and 1,4,1,2:i:-) [3].

With respect to the prevalence on positive farms, the EU baseline study performed in 2008 reported an average of $33.3 \%$ herds that tested positive for Salmonella, with a wide range among member states $(0 \cdot 0-55 \cdot 7 \%)$. The most recent report on zoonoses and zoonotic agents in the EU, reported a $10 \cdot 1 \%$ herd prevalence of Salmonella among nine countries in 2014 [3]. However, a comparison between the on-farm and abattoir prevalence of infection in pigs revealed that the on-farm prevalence is often underestimated. In Germany, the on-farm prevalence of infection in pigs, based on faecal analysis, was 5.58\%; however, the caecal contents of $24.9 \%$ of slaughtered pigs were found to be Salmonella positive [24]. In a study by Hurd et al. [20], the abattoir prevalence of Salmonella in pigs was $39.9 \%$, as opposed to an on-farm prevalence of $5 \cdot 3 \%$, a disparity that was probably due to the sample type ( $1 \mathrm{~g}$ faecal swabs on farm vs. $10 \mathrm{~g}$ caecal contents after necropsy). The sensitivity of faecal samples collected on farm was particularly poor for pigs infected in the lymph nodes $(0 \%$ on farm, $12 \cdot 2 \%$ at abattoir). The sensitivity of faecal culture increases only twofold with a $10 \mathrm{~g}$ sample, as compared with a $1 \mathrm{~g}$ sample; thus, low faecal volume might partially explain the low sensitivity of samples collected from live pigs on farm [30]. Indeed, other factors might contribute to this discrepancy, such as the incidence of recent infections during transportation or slaughter [21]. Otherwise, the presence of latent undetectable carriers among infected pigs is a common characteristic in the epidemiology of Salmonella [20]. Moreover, intermittent shedding by pigs is a common feature that can interfere with monitoring and research programmes on Salmonella infection and the determination of health status in animals [31].

Prevalence can vary at the farm level, depending on various factors, such as feeding practices, including the degree to which the feed is ground, and the $\mathrm{pH}$ and type of feed; management procedures, such as continuous or all-in/all-out production system; different types of herds (farrow-to-finish herds or fattening herds); size of the herd; as well the level of hygiene and general health status of the pigs. The provision of safe feed is the first step in ensuring safe food, especially in a 'farm-to-fork' concept [32]. Therefore, pig feed should be Salmonella-free to guarantee a safer pork chain.

Wet feed has been demonstrated to reduce the risk of Salmonella infection, in comparison to pelleted feed, probably because of a fermentation step and consequent growth of lactic acid bacteria and yeasts [33]. The large amounts of organic acids produced, thus exert a protective effect, in a similar manner to the addition of organic acids to water [34] and feed [35]. In contrast, pelleted feed is considered one of the most consistently reported risk factors for Salmonella shedding in pigs [36]. In addition, feed particle size can affect the prevalence of Salmonella isolated from the gastrointestinal tract of pigs. In comparison to finely ground feed $(<0 \cdot 20-1 \cdot 00 \mathrm{~mm})$, coarsely ground feed $(2.00->3.15 \mathrm{~mm})$ reduces the prevalence of Salmonella, by enhancing the fermentation of starch in the gut [37].

Regarding the influence of $\mathrm{pH}$, values of 4.5 or lower effectively inhibit Salmonella both in the feed and in the gastrointestinal tract of pigs. Fermented liquid feed can yield such values, and improves the performance of sucklings, weaners and grower-finishers. 
Feeding pigs fermented liquid feed prevents the growth and proliferation of pathogens, such as Escherichia coli and Salmonella, in the gut by reducing the $\mathrm{pH}$ in the stomach [38]. This is particularly important, because Salmonella has been detected in pig feed. In 2014, for example, some member states of the EU reported various serovars, including $S$. Typhimurium, $S$. Enteritidis, $S$. Give, $S$. Agona, $S$. Anatum and $S$. Mbandaka in the feed of pigs [3]. However, despite several studies on various interventions in feeding practices, there remains a lack of strong evidence of the effects between any association (acidification of liquid or pelletised feed vs. mash; coarse vs. finely ground feed; wet $v s$. dry feed, etc.) in reducing the prevalence of Salmonella on farm. Indeed, researchers do not consistently support the association between non-pelleted feed and a reduction in the prevalence of Salmonella in pigs [39].

The all-in/all-out management system reportedly has a protective effect against Salmonella infection [40], particularly when practised by the entire barn more than by single rooms [41]. The protective effect has also been observed when animals from different age groups are housed separately [42]. Contact with other species, as dogs and cats, can introduce the microorganism on farms, thereby increasing the risk of Salmonella infection [42]. Management practices also encompass the design of pen walls (solid, spindles or combination) and type of floor (fully slatted floors $v s .<50 \%$ slatted floors can significantly reduce the prevalence of Salmonella) [13]. Nose-to-nose contact between pens is an important risk factor, as pens that allow direct contact among pigs are more likely to be Salmonella positive than those without such contact [36]. Poor pen cleaning and disinfection, and poor biosecurity measures are also important risk factors for the persistence of Salmonella at the farm level [43]. Cleaning by pressure washing with water, disinfection with chemicals and effective rodent control programmes are effective hygienic measures that should be adopted on farms [41]. Nevertheless, the resistance of Salmonella to some disinfectants, such as glutaraldehyde, formaldehyde and hydroxide peroxide at a concentration of $1 \cdot 0 \%$, make their use ineffective in field conditions, when it is protected by the development of a biofilm [44].

The prevalence of Salmonella shedding in pigs is higher in finishing farms (open farms) than in farrow-to-finish farms (closed farms) [45]. A Belgian study demonstrated that finishing farms were two times more likely to have Salmonella shedders than farrow-to-finish farms, with positive rates of $10 \cdot 3 \%$ and $5.4 \%$, respectively (mean within-herd prevalence of $7.8 \%$ ) [46]. Other authors have observed similar findings [45]. One possible explanation is that pigs raised in fattening farms originate from the piggery units of other farms. Upon arrival, they are frequently mixed with piglets of different origin, thus sharing the various health conditions of each (including Salmonella infection). Furthermore, transportation from piggeries to the finishing farms could be a stressful event that promotes the shedding of Salmonella by carrier animals, and the spread of infection throughout the barns [46].

In farrow-to-finish herds, where sows maintain the infection and excrete Salmonella particularly after weaning [47], prevalence might be influenced by herd size. Dors et al. [48] observed that prevalence in herds with more than 200 shedding sows was higher than in smaller herds. Furthermore, the size of finishing herds could increase the risk of development of the Salmonella carrier status in pigs, as this is usually higher in units that slaughter more than 3500 pigs per year [41].

\section{Salmonella during transportation and holding (the harvest stage)}

The harvest stage refers to the part of the food chain that includes transportation of the animals from the farm, the lairage period, the slaughtering process and the cooling of carcasses [22].

During this stage, asymptomatic pigs could begin to shed Salmonella after having left the farm, owing to stress factors that are linked to group housing, transportation and holding at the slaughterhouse. Transportation significantly increases Salmonella shedding, thus, shedders become an important source of Salmonella to other pigs that are being transported $[21,49]$. Stress can be caused by rough handling of the pigs at the time of loading and unloading, high stocking density during transport, long duration of transport, poor driver skills, adverse weather conditions and feed withdrawal. A relatively long feed withdrawal period, which is usually $12-18 \mathrm{~h}$ before transport, could be associated with changes in the gut microbiota, and elevated levels of Salmonella in the faeces [50].

Another factor that could influence the prevalence of infection among pigs at slaughter is the lairage duration. A positive relationship exists between the time spent at lairage and the frequency of Salmonella 
detection in the lymph nodes, probably due to increased opportunity for invasion of the mesenteric lymph nodes (MLN) under conditions of prolonged stress. Pigs held for $12 \mathrm{~h}$ or more showed a greater chance of acquiring Salmonella from the lairage environment $(16.7 \%)$, as compared with pigs held for $1-3 \mathrm{~h}$ $(11 \cdot 1 \%)$ [51].

Transportation and lairage conditions are thus important steps in the pork production chain that can increase the number of infected animals that are slaughtered. However, some studies suggest that external sources of infection might have a greater impact than stress, in increasing the detection of Salmonella at slaughter. For example, in a comparison of on-farm and slaughtered pigs, Hurd et al. [21] reported a sevenfold increase, and detected a variety of Salmonella serovars in necropsied animals, that had not been isolated from pigs on the farm. Such infections could be acquired before slaughter from various shedder pigs in transport trucks or the lairage environment, as infection of the gastrointestinal tract and infiltration of the associated lymph nodes can occur in as little as $2 \mathrm{~h}$ [52]. Rapid infection during transportation, and particularly during holding of pigs, is a major cause of increased Salmonella prevalence. Generally, the holding pen could be an important control point for Salmonella in the pork production chain [21]. Reduced exposure in trucks and holding pens is more likely to reduce Salmonella prevalence, than attempts to minimise stress, which is inevitable during transportation and lairage [53]. To facilitate the movement of pigs, stress at lairage can be kept under control by using well-designed infrastructure, well-lit corridors and minimal and careful handling of pigs, as specified by Regulation (EC) 1069/2009 [54], and discussed by some authors [55]. In addition, showering pigs when the temperature rises to $>10^{\circ} \mathrm{C}$ [56] improves animal welfare at lairage. However, these measures can successfully reduce infections in pigs, only if the lairage environment is not already contaminated with Salmonella, thus posing a challenge for all slaughterhouses [55]. Contamination of the lairage might be responsible for oral infections in holding pigs, as well as skin contamination, which is directly related to carcass contamination during the slaughter process. In a comparison of carcasses with contaminated skin and those without, the probability of surface contamination of the carcass was reduced from $59 \%$ to $35 \%$, respectively [57]. Furthermore, failure to dehair the carcass can significantly increase the number of contaminated carcasses [58].

\section{Salmonella at slaughter (the harvest stage)}

The prevalence of Salmonella contamination in pork carcasses has been extensively studied in most European countries. Detection rates vary among studies, but all underline that Salmonella can be frequently isolated from MLN and faecal samples of pigs. Indeed, detection of Salmonella in the lymph nodes is frequently considered the 'gold standard' for definition of the carrier state at slaughter [22]. Alternatively, caecal material or faeces can be tested for carriage of Salmonella in pigs [22]. According to recent studies, the prevalence of Salmonella in MLN ranges from $7 \cdot 4 \%$ to $26 \cdot 0 \%[14,24,51,59-62]$ in EU countries (Table 1). In 2014, very low levels of prevalence were detected in Sweden $(0.0 \%)$ and Finland $(0.03 \%)$, where control and eradication programmes reported the presence of Salmonella in the lymph nodes of finishing pigs [3]. Different surveys have reported prevalence at around $20-30 \%$ in faecal contents $[11,24,63,64]$ (Table 1). Furthermore, monitoring programmes based in the analysis of pig faeces in Denmark and Estonia reported rates of $21.6 \%$ and $27 \cdot 3 \%$, respectively [3]. Other data on the prevalence of Salmonella in pigs at slaughter are also available based on examination of the tonsils [24, 61, 63] (Table 1), mandibular lymph nodes [61], gall [24], heart and tongue [63].

Routes of contamination might be related to the pig or the slaughter environment. Contamination from the faeces of pigs that have been slaughtered on the same day might occur, with a typical distribution of Salmonella to the distal and medial surfaces of carcasses [65]. Contamination of carcasses with Salmonella on the skin of pigs has been demonstrated [58], but is probably less significant than faecal contamination [65]. In addition to the pig, the slaughter environment, in which microflora pose a potential risk for carcass contamination, is a major source of Salmonella [66]. Equipment, such as carcass splitters and belly openers, might be contaminated with Salmonella from fluids dripping from the carcasses onto the machines. Consequently, Salmonella on contaminated equipment could be transferred to other carcasses that are subsequently slaughtered [65]. Salmonella can also be spread by workers at the abattoir, as the hands of meat handlers can be frequently contaminated [59].

A marked reduction has been observed in the prevalence of Salmonella and the number of contaminated carcasses as the slaughtering process progresses 
Table 1. Prevalence of Salmonella in MLN, faeces, tonsils and carcasses of pigs at slaughter in different EU countries

\begin{tabular}{|c|c|c|c|c|c|c|}
\hline \multicolumn{4}{|c|}{ Prevalence $(\%)$} & \multirow[b]{2}{*}{ Country } & \multirow[b]{2}{*}{ Years } & \multirow[b]{2}{*}{ Reference } \\
\hline MLN & Faeces & Tonsils & Carcasses & & & \\
\hline $26 \cdot 0$ & & & $16 \cdot 0$ & Portugal & $2007-2008$ & [58] \\
\hline $22 \cdot 0$ & $22 \cdot 0$ & & $15 \cdot 0$ & UK & 2006-2007 & [59] \\
\hline $19 \cdot 9$ & & & & Italy & 2013-2014 & [50] \\
\hline $18 \cdot 8$ & & $9 \cdot 9$ & $12 \cdot 9$ & Portugal & 2003-2004 & {$[60]$} \\
\hline $17 \cdot 7$ & & & & Belgium & 2007 & {$[61]$} \\
\hline $14 \cdot 5$ & 24.9 & $20 \cdot 1$ & $4 \cdot 6$ & Germany & 2005-2006 & [24] \\
\hline $7 \cdot 4$ & & & $3 \cdot 2$ & Denmark & 2006-2007 & [14] \\
\hline $0 \cdot 03$ & & & & Finland & 2014 & [3] \\
\hline \multirow[t]{7}{*}{$0 \cdot 0$} & & & & Sweden & 2014 & [3] \\
\hline & $30 \cdot 5$ & & & UK & 2013 & [62] \\
\hline & $27 \cdot 3$ & & & Estonia & 2014 & [3] \\
\hline & $23 \cdot 0$ & & $5 \cdot 3$ & UK & $1999-2000$ & [11] \\
\hline & $21 \cdot 6$ & & & Denmark & 2014 & [3] \\
\hline & $21 \cdot 5$ & $10 \cdot 4$ & $10 \cdot 9$ & Italy & 2005-2008 & [63] \\
\hline & & & $5 \cdot 0$ & Ireland & n.s. & [69] \\
\hline
\end{tabular}

EU, European Union; MLN, mesenteric lymph nodes; n.s., not shown.

[67], because of the steps taken to reduce bacterial flora on the skin of pigs. In one study examining a relatively large number of Salmonella-positive carcasses, the prevalence of Salmonella contamination was $96.6 \%$ at exsanguination and $35.9 \%$ after slaughter. During the slaughter process, skin contamination was reduced from $96 \cdot 6 \%$ to $16 \cdot 2 \%$, but crosscontamination via equipment was responsible for the final number of Salmonella-positive carcasses reported [68]. Several authors have outlined that the main means of contamination is probably the result of a continuous cycle between pigs, the environment and the carcasses $[62,69]$.

Different levels of prevalence have been detected in pig carcasses in EU countries, ranging from $3 \cdot 2 \%$ to $16 \%[11,14,59-61,64,70]$ (Table 1). Data from several countries in 2014, reported by the EFSA and ECDC are shown in Table 2. The differences observed could be attributed to several factors, such as the number of carrier pigs introduced to the slaughter line; implementation of effective steps for decontamination including dehairing, polishing and flaming; maintenance of good hygienic standards at slaughter; crosscontamination between carcasses and equipment; cross-contamination among carcasses; presence of resident slaughterhouse microflora and passive transmission via the hands of workers. Regulation (EC) 2015/1474 [71] regarding the use of recycled hot water to remove microbiological surface contamination
Table 2. Prevalence of Salmonella in pig carcasses at slaughter in 2014

\begin{tabular}{lll}
\hline \hline Prevalence $(\%)$ & Number of tested animals & Country \\
\hline $12 \cdot 75$ & 447 & Belgium \\
$0 \cdot 57$ & 5392 & Czech Republic \\
$0 \cdot 98$ & 10350 & Denmark \\
$3 \cdot 12$ & 385 & Estonia \\
$0 \cdot 0$ & 6398 & Finland \\
$0 \cdot 35$ & 1438 & Hungary \\
$0 \cdot 44$ & 450 & Latvia \\
$17 \cdot 41$ & 293 & Spain \\
$0 \cdot 00$ & 4921 & Sweden \\
$0 \cdot 00$ & 3025 & Norway \\
\hline
\end{tabular}

Sampling unit: single pig [3].

from carcasses has recently offered increased opportunity to reduce the prevalence of Salmonella.

Because the pathogen is not only introduced to the slaughter line by the pigs, but could persist in the slaughterhouse environment, or be acquired during transportation and holding, the serovars isolated from on-farm samples can vary widely from those isolated after slaughter [24, 25, 49, 72]. The most commonly reported Salmonella serovars isolated from carcasses at slaughter are Derby, Typhimurium, Typhimurium monophasic variant, Rissen, Brandenburg, London, Manhattan, Muenchen and Stanley [51, 65]. The monophasic variant of $S$. Typhimurium (but not the biphasic $S$. Typhimurium) has been identified in pigs at slaughter 
[51]. It is the most commonly isolated serovar in some countries, such as the UK, where it accounted for $32.9 \%$ of the serovars isolated from pigs in 2013 [73]. The rise in incidence of the monophasic variant of $\mathrm{S}$. Typhimurium might be related to a novel clonal group that is characterised by the tetra-resistant pattern ASSuT (ampicillin, streptomycin, sulphonamides, tetracycline), which emerged during the 2000s in some EU countries, and has become particularly common in some member states, such as Italy, Denmark, the UK and Germany. In this clonal group, multidrug resistance is conferred by a new genomic island and the pattern ASSuT can be used for provisional identification of the isolates $[74,75]$.

\section{Salmonella in the post-harvest stage: the EU Regulation (EC) No 2073/2005 criteria}

The criteria for Salmonella in foodstuffs, laid down by Regulation (EC) No 2073/2005 [76], have been in force since 1 January 2006. In member states of the EU, most national monitoring programmes for Salmonella in pork and pork products are based on the collection of swab samples of the carcass at the slaughterhouse, and/or meat samples at the processing plants. Regulation (EC) No 217/2014 [77] is a revision of Regulation 2073/2005 [76] and serves to reduce the acceptable number of Salmonella-positive pig carcasses from 5 out of $50(10 \%)$ to 3 out of $50(6 \%)$. Therefore, food business operators have to implement appropriate interventions to reduce the number of contaminated carcasses.

The studies on pork and ready-to-eat pork products have not been uniformly conducted among various EU countries, and show differences in sampling procedures, types of end-products and detection methods. Thus, consideration was given only to the most recent data provided by EFSA, which reported an overall Salmonella prevalence of $0.5 \%$ in fresh pork and $0.7 \%$ in ready-to-eat minced meat, meat preparations and meat products. Despite these relatively low numbers, pork and pork products, especially if consumed raw or undercooked, frequently represent a source of non-typhoidal Salmonella strains to humans [3].

\section{PIGS AS A SOURCE OF SALMONELLA TO HUMANS}

Besides poultry, laying hens and turkeys, pigs are one of the major animal species that are responsible for the transmission of Salmonella to humans. However, their role in food-borne salmonellosis in humans varies among EU countries. Salmonella source attribution studies estimate that pigs are a major source of salmonellosis in Southern Europe, accounting for $43.6 \%$ of all cases, whereas laying hens are the most significant source in Northern, Eastern and Western EU countries accounting for between 30.0\% and $57 \cdot 6 \%$ of all reported cases [1]. Overall, laying hens (via the eggs) represents the most important source of human salmonellosis in the EU, accounting for $42.4 \%$ of all cases, followed by pigs, accounting for $31 \cdot 1 \%$. Pigs are the major contributors of salmonellosis in eight countries, namely Belgium, Cyprus, Finland, France, Ireland, Italy, Poland and Sweden, whereas disease attribution to laying hens and pigs are similar in the Netherlands [78].

The role of pork in food-borne outbreaks of human salmonellosis has been demonstrated in several investigations, and many isolates detected in pigs have been responsible for human cases [51]. Overall, pork is ranked third among food categories that show strong epidemiological evidence of an association with human outbreaks of salmonellosis. The highest ranked food category is eggs and egg products, and the second, baked products, which were each responsible for $44.0 \%$ and $12.9 \%$ of outbreaks of human salmonellosis in 2014, respectively. Pork and pork products show strong evidence of an association with $9 \cdot 3 \%$ of outbreaks reported in the EU. Pork is therefore the most significant source of meat that is responsible for the transmission of Salmonella to consumers [3].

Furthermore, when the source is known, the category 'pork and products thereof' is the mode of transmission most frequently associated with $S$. Typhimurium outbreaks [3]. Because $S$. Typhimurium and its monophasic variant are prevalent both on farm and at slaughter, isolation of this serovar in strong evidence outbreaks attributed to the consumption of pork is not surprising. In 2014, the most common Salmonella serovars isolated from pork and pork products in various EU countries were $S$. Typhimurium (28.3\%), $S$. Derby $(23 \cdot 6 \%), S$. Typhimurium monophasic variant $(18 \cdot 0 \%), S$. Infantis (8.8\%), $S$. Rissen $(4 \cdot 9 \%), S$. Brandenburg $(4 \cdot 9 \%)$ and $S$. Enteritidis $(2 \cdot 1 \%)$. Although $S$. Typhimurium was the most commonly isolated serovar from both pigs and pork, the isolation of $S$. Typhimurium in pigs was significantly higher $(54 \cdot 7 \%)$ than it was in pork. This could be attributed to the fact that some countries submit more data on Salmonella from pigs than from pork, thus reducing the reported prevalence of $S$. Typhimurium in pork [3]. 
With respect to human salmonellosis, recent information on Salmonella serovars collected at the EU level, highlights the most common as $S$. Enteritidis and $S$. Typhimurium, which account for $44.4 \%$ and $17 \cdot 4 \%$, respectively, of all serovars reported in 2014 . These serovars have been identified in all member states of the EU. The monophasic variant of $S$. Typhimurium represents the third most common serovar, responsible for $7 \cdot 8 \%$ of all notified human cases. In order of frequency, $S$. Infantis $(2 \cdot 5 \%), S$. Stanley $(1 \%)$ and $S$. Derby $(1 \%)$ are reported in fewer confirmed human cases, but are more widely distributed in several countries [3]. The pig-adapted $S$. Choleraesuis causes a serious infection in humans that is associated with high mortality, tends to be more invasive and cause fewer gastrointestinal symptoms than most other serovars [79]. Fortunately, it is not a common serovar in humans [3], despite the reappearance of the Kunzendorf variant within recent years [12].

European data on the most frequently isolated Salmonella serovars, confirm that they can all be detected in pigs and pork, but in varying proportions. Otherwise, to establish possible epidemiological correlations between porcine and human strains, genotyping of the isolates responsible for human cases that have also been detected in suspicious food sources, should be performed. Salmonella isolates can be subtyped by pulsed-field gel electrophoresis (PFGE), multiple-locus variable-number tandem-repeats analysis (MLVA) and patterns of antimicrobial resistance, in order to characterise the isolates that are associated with outbreaks. For example, in 2011, one major outbreak and several geographically dispersed smaller outbreaks that had been linked to pork were traced back to a butcher's shop and a pig farm in England, where a multidrug-resistant ASSuTTm (ampicillin, streptomycin, sulphonamides, tetracycline, trimethoprim) strain of $S$. Typhimurium phage type 120 (DT120) was isolated [80]. An outbreak at a wedding in Italy in 2011 was caused by the monophasic variant of $S$. Typhimurium 4,[5],12:i:-, of the rare phage type DT7a [81]. Since the source was identified in a cooked pork product, epidemiological investigations on the farm of origin revealed that the pigs carried a different serovar (biphasic $S$. Typhimurium) of the same phage type DT7a in their faeces. To identify specifically the most suitable subtyping methods by which the isolates associated with this outbreak could have been characterised, isolates from humans, pork and pigs were typed using XbaI PFGE, MLVA and patterns of antimicrobial resistance. That study could not demonstrate whether isolates of the outbreak were directly related to isolates from the animals, but suggested that MLVA in particular, could be a reliable tool to support outbreak investigations and assess the genetic relatedness among Salmonella isolates [81]. In Italy two outbreaks of $S .4,[5], 12: \mathrm{i}:-$ DT193 were found to be caused by different strains, as the isolates were characterised using both BlnI-PFGE and MLVA [82]. In contrast, $X b a \mathrm{I}$ PFGE showed that the strains associated with the outbreaks were undistinguishable [82]. Characterisation of Salmonella is essential for proper identification, tracking and intervention during food-borne outbreaks. The phenotypic methods that traditionally provide important epidemiologic data during outbreak investigations have reduced value as typing tools for the surveillance and detection of common sources during outbreaks [81]. Within recent years, WGS (whole-genome sequencing) has increasingly become more readily available, and is routinely used as a powerful tool in diagnostic and epidemiological investigations during outbreaks and in various studies on infectious bacteria [83].

Molecular investigations and studies in antimicrobial resistance have been conducted both in foodborne outbreaks [81-83] and in research studies [51, 84-87], demonstrating the epidemiological connection between porcine and human compartments. In Italy, a comparison of $X b a$ I PFGE profiles of porcine and human Salmonella isolates demonstrated shared profiles of $S$. Derby, $S$. 4,[5],12:i:-, $S$. Rissen, $S$. Manhattan, $S$. Brandenburg, $S$. Livingstone, $S$. London and $S$. Muenchen [51]. The relationship between porcine and human cases of salmonellosis ( $S$. Derby) has also been demonstrated in France, in a study that typed porcine and human isolates with $X b a \mathrm{I}, B \ln \mathrm{I}$ and SpeI PFGE [84]. Most $S$. Derby isolates from pigs and humans were found to be resistant to streptomycin, sulphonamides and tetracycline (R-type SSuT) [84]. The whole-genome sequence of the most commonly detected strain of $S$. Derby in French pigs was recently characterised. The porcine isolate showed PFGE profiles and patterns of resistance $(\mathrm{S}, \mathrm{SSu}, \mathrm{T})$ that have also been frequently identified in human isolates of Salmonella [84]. In Switzerland, two distinct clones of $S$. 4,[5],12:i:-, showing the ASSuT and SSuT patterns of antimicrobial resistance, were identified among human and porcine isolates [86].

Food-borne outbreaks of $S$. Typhimurium associated with pork products have been frequently reported, and 
have been associated with the consumption of dried pork sausages in Spain [88], pork in England [80], smoked pork tenderloin [89], ready-to-eat spreadable pork sausage (Teewurst) [90] and salami produced with pork and venison in Denmark [91], and pork salami in Italy [92]. $S$. Typhimurium monophasic variant was identified as the causative agent of an outbreak in Germany following the consumption of minced pork [93] and in Italy following the consumption of cooked pork [81]. In another outbreak in Spain, both monophasic and biphasic S. Typhimurium strains, as well as S. Derby, were associated with the consumption of dried pork sausages [88].

$S$. Derby is strongly associated with pigs and pork products. In 2013, a food-borne outbreak of $S$. Derby affected 145 elderly patients and caused one death in Berlin, Germany, following the consumption of Teewurst [94]. Another outbreak was reported in France during the same year, and $S$. Derby was isolated from a typical meal, in which crosscontamination of the meat (beef and pork) probably occurred during preparation [73].

In 2014, Germany reported one food-borne outbreak of $S$. Muenchen that affected 164 people, of which four persons died. This outbreak was associated with the consumption of mostly raw pork products, in private households and a residential institution. A comprehensive investigation was conducted and the outbreak strain was detected in various food samples and in primary pig production facilities [3].

Over the last decade, Germany, Italy, the UK and Portugal have reported an increased prevalence of $S$. Typhimurium monophasic variant in pig populations [51, 74, 95-97], and consequently in humans affected by salmonellosis [3]. Another emerging serovar related to the pig is $S$. Brandenburg [51, 98], which has been increasingly isolated from humans affected by the disease $[3,51,73]$. Although it is not among the most frequently detected serovars in pigs in Europe generally, $S$. Rissen is common in pigs in Southern Europe $[51,59]$. It is among the most frequently detected serovars in humans and pork production systems in several parts of the world, particularly Asia, and frequently detected in the USA [99]. Over the last few years, $S$. Rissen has been rarely detected in the EU, and the number of confirmed human cases is relatively low [3]. As Far-Eastern strains of epidemic multidrug-resistant $S$. Rissen have been isolated from pigs in some countries, for example Spain [100], further dissemination to other member states is possible.

\section{CONCLUSIONS}

Salmonellosis has a major impact on human health, being the second most frequently reported zoonosis in EU countries [3]. Among food animals, pigs are estimated to be the second largest contributor to human cases of salmonellosis in the EU, after laying hens. For this reason, the symptomatic or asymptomatic carriage by pigs, epidemiology of the infection in herds, distribution of Salmonella serovars among pigs and contamination routes at slaughter have all been intensively investigated.

Many risk factors exist on the pig farm, including those related to feed, animal management, hygiene and biosecurity. The complexity of interactions among these factors can either amplify or reduce the prevalence Salmonella in pigs (Fig. 1). Consequently, implementing a unique strategy to reduce the levels of Salmonella in the pork production chain is a major challenge, especially as it relates to farm management, which over several years, can progressively change risk factor patterns [42]. Transportation practices and holding at slaughter are often responsible for contamination among animals, and these factors largely influence the prevalence of Salmonella in positive pigs entering the slaughter chain (Fig. 1). At slaughter, dehairing, polishing, flaming and sectioning operations can all affect the bacterial contamination of pork carcasses in several ways, and these processes generally do not include any hazard eliminating points [101]. Furthermore, one of the main risk factors for contamination is the persistence of Salmonella in the slaughter environment and the subsequent spread of variable serovars to pig carcasses. Nevertheless, many studies have demonstrated that good hygienic practices at slaughter are more effective in reducing the prevalence of Salmonella than on-farm interventions [102]. Abattoir interventions and their role in Salmonella control on pig carcasses are summarised in Figure 1.

Within recent years, Salmonella transmission from pigs to humans via the food chain has often been demonstrated, both in food-borne outbreaks and in epidemiological studies, with the aid of molecular techniques that are able to identify the strains responsible for porcine and human infections [51, 80-87]. The EU Regulation (EC) No. $2160 / 2003$ [103] on zoonoses targets the reduction of Salmonella in animals and food products of animal origin during all phases of production, transformation and distribution, with an emphasis on primary production. Member states 


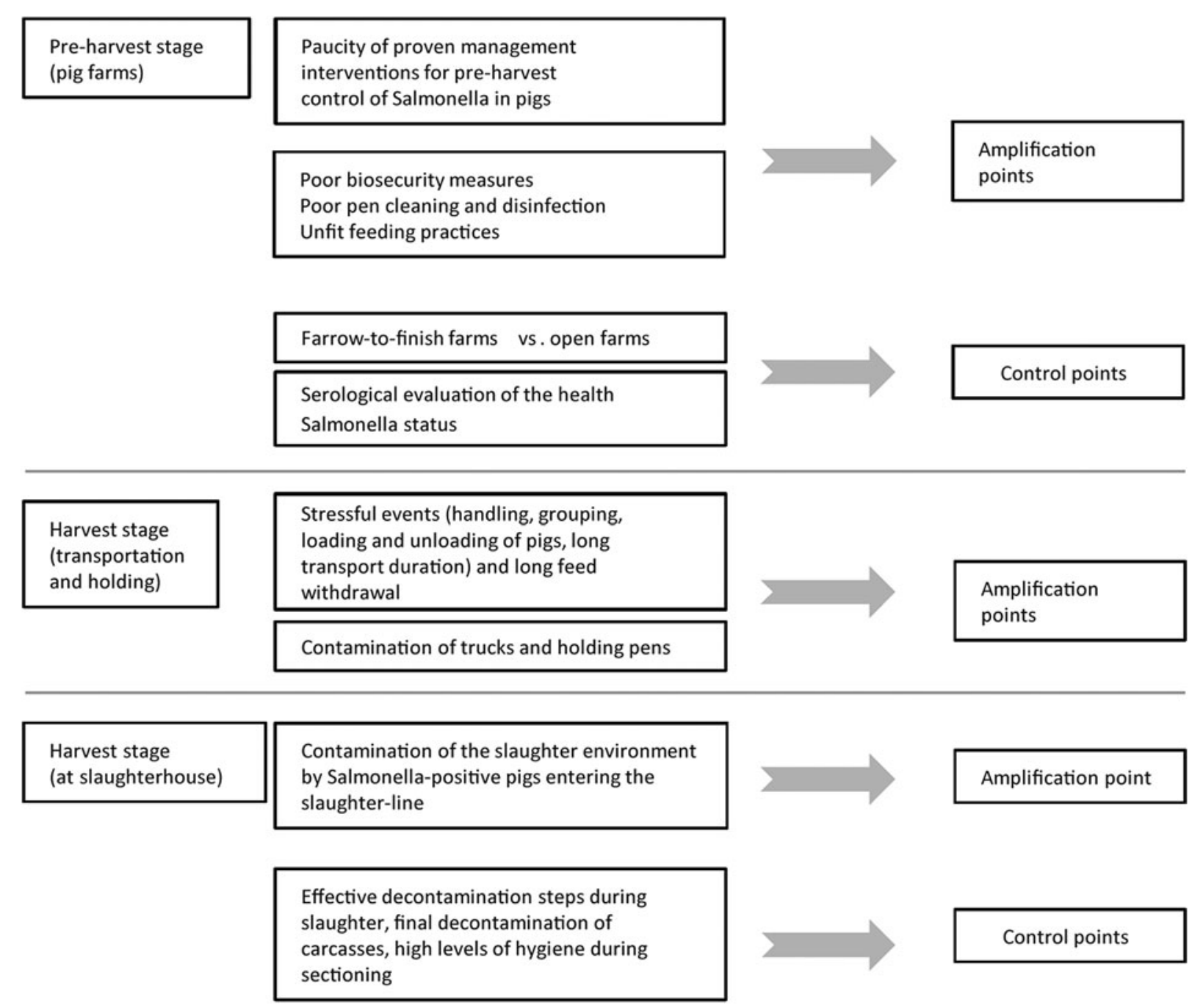

Fig. 1. Salmonella amplification and control points in the pork production system.

of the EU are required to take effective measures to control Salmonella in specific animal species (including pigs), and thereby lower the incidence of human salmonellosis. The interventions should be done on farm, at the slaughterhouse, or a combination of the two, as agreed by the member states [28]. Although quantitative microbiological risk assessment has shown that specific interventions at slaughter are more likely to produce a more significant reduction in cases of human illness than interventions at the level of primary production [104, 105], evaluation of the health status of pigs on the farm is still highly recommended. In some EU countries, such as Germany and Denmark, specific monitoring programmes categorise herds through a nationwide sampling scheme, based on Salmonella seroprevalence in pigs. Herds are categorised according to the percentage of ELISA (enzyme-linked immunosorbent assay) seropositive samples present [106, 107]. Serological monitoring aims to estimate the risk for Salmonella at the level of the herd, and reduce the risk of introducing the pathogen into the meat production chain [108]. This type of monitoring should be considered a strategic tool for food safety in all European countries.

\section{ACKNOWLEDGEMENTS}

This research received no specific grant from any funding agency, commercial or not-for-profit sectors.

\section{DECLARATION OF INTEREST}

None. 


\section{REFERENCES}

1. Pires SM, de Knegt L, Hald T. Estimation of the relative contribution of different food and animal sources to human Salmonella infections in the European Union. Søborg, Denmark: National Food Institute, Technical University of Denmark. EFSA Supporting Publications 2011. Published online: 25 August 2011. doi: 10.2903/ sp.efsa.2011.EN-184.

2. Hendriksen RS, et al. Global monitoring of Salmonella serovar distribution from the World Health Organization Global Foodborne Infections Network Country Data Bank: results of quality assured laboratories from 2001 to 2007. Foodborne Pathogens and Disease 2011; 8: 887-900. doi: 10.1089/fpd.2010.0787.

3. European Food Safety Authority, European Centre for Disease Prevention and Control. The European Union summary report on trends of zoonoses, zoonotic agents and food-borne outbreaks in 2014. EFSA Journal 2015; 13: 4329. doi: 10.2903/j.efsa.2015.4329.

4. Su LH, Chiu CH. Salmonella: clinical importance and evolution of nomenclature. Chang Gun Medical Journal 2007; 30: 210-219.

5. Chen HM, et al. Nontyphoidal Salmonella infection: microbiology, clinical features, and antimicrobial therapy. Pediatric Neonatology 2013; 54: 147-152. doi: 10.1016/j.pedneo.2013.01.010.

6. Deen $\mathbf{J}$, et al. Community- acquired bacterial bloodstream infections in developing countries in south and southeast Asia: a systematic review. Lancet Infectious Diseases 2012; 12: 480-487. doi: 10.1016/S1473-3099 (12)70028-2.

7. Uzzau S, et al. Host adapted serotypes of Salmonella enterica. Epidemiology and Infection 2000; 125: 229-255.

8. Wilcock BP, Schwartz K. Salmonellosis. In: Leman AD, Straw BE, Mengeling WE, D'Allaire S, Taylor DJ, eds. Diseases of swine, 7 th edn. Ames: Iowa State University Press, 1992, pp. 570-583.

9. Gray JT, et al. Natural transmission of Salmonella choleraesuis in swine. Applied and Environmental Microbiology 1996; 62: 141-146.

10. Fedorka-Cray PJ, Gray JT, Wray C. Salmonella infections in pigs. In: Wray C, Wray A, eds. Salmonella in Domestic Animals. Wallingford: CAB International, 2000, pp. 191-207.

11. Davies RH, et al. National survey for Salmonella in pigs, cattle and sheep at slaughter in Great Britain (1999-2000). Journal of Applied Microbiology 2004; 96: 750-760.

12. Pedersen K, et al. Reappearance of Salmonella serovar Choleraesuis var. Kunzendorf in Danish pig herds. Veterinary Microbiology 2015; 176: 282-291. doi: 10.1016/j.vetmic.2015.01.004.

13. Nollet $\mathbf{N}$, et al. Risk factors for the herd-level bacteriologic prevalence of Salmonella in Belgian slaughter pigs. Preventive Veterinary Medicine 2004; 65: 63-75. doi: 10.1016/j.prevetmed.2004.06.009.

14. Argüello $\mathbf{H}$, et al. Prevalence, serotypes and resistance patterns of Salmonella in Danish pig production. Research in Veterinary Science 2013; 95: 334-342. doi: 10.1016/j.rvsc.2013.04.001.
15. Nathues C, et al. Campylobacter spp., Yersinia enterocolitica, and Salmonella enterica and their simultaneous occurrence in German fattening pig herds and their environment. Journal of Food Protection 2013; 76: 1704-1711. doi: 10.4315/0362-028X.JFP-13-076.

16. Wales A, et al. Investigation of the distribution of Salmonella within an integrated pig breeding and production organisation in the United Kingdom. ISRN Veterinary Science 2013. Published online: 20 November 2013. doi: 10.1155/2013/943126.

17. García-Fierro R, et al. Antimicrobial drug resistance and molecular typing of Salmonella enterica serovar Rissen from different sources. Microbial Drug Resistance 2016; 22: 211-217. doi: 10.1089/ mdr.2015.0161.

18. Boyen F, et al. Non-typhoidal Salmonella infections in pigs: a closer look at epidemiology, pathogenesis and control. Veterinary Microbiology 2008; 130: 1-19. doi: 10.1016/j.vetmic.2007.12.017.

19. Fedorka-Cray PJ, et al. Alternate routes of invasion may affect pathogenesis of Salmonella typhimurium in swine. Infection and Immunity 1995; 63: 2658-2664.

20. Hurd HS, et al. Estimation of the Salmonella enterica prevalence in finishing swine. Epidemiology and Infection 2004; 132: 127-135.

21. Hurd HS, et al. Salmonella enterica infections in market swine before and after transport and holding. Applied and Environmental Microbiology 2002; 68: 2376-2381.

22. European Food Safety Authority. Risk assessment and mitigation options for Salmonella in pig production. EFSA Journal 2006; 341: 1-131. doi: 10.2903/j. efsa.2006.341.

23. Côté S, et al. Distribution of Salmonella in tissues following natural and experimental infection in pigs. Canadian Journal of Veterinary Research 2004; 68: 241-248.

24. Visscher CF, et al. Serodiversity and serological as well as cultural distribution of Salmonella on farms and in abattoirs in Lower Saxony, Germany. International Journal of Food Microbiology 2011; 146: 44-51. doi: 10.1016/j.ijfoodmicro.2011.01.038.

25. Merialdi G, et al. Longitudinal study of Salmonella infection in Italian farrow-to-finish swine herds. Zoonoses and Public Health 2008; 55: 222-226. doi: 10.1111/j.1863-2378.2008.01111.x.

26. Magistrali C, et al. Contamination of Salmonella spp. in a pig finishing herd, from the arrival of the animals to the slaughterhouse. Research in Veterinary Science 2008; 85: 204-207. doi: 10.1016/j.rvsc.2007.12.002.

27. Denis M, et al. Distribution of serotypes and genotypes of Salmonella enterica species in French pig production. Veterinary Record 2013; 173: 370. doi: 10.1136/ vr.101901

28. European Food Safety Authority. Report of the Task Force on Zoonoses Data Collection on the Analysis of the baseline survey on the prevalence of Salmonella in slaughter pigs, in the EU, 2006-2007-Part A: Salmonella prevalence estimates. EFSA Journal 2008; 8: 135 r, 111 pp. doi: 10.2903/j.efsa.2008.135r. 
29. European Food Safety Authority. Analysis of the baseline survey on the prevalence of Salmonella in holdings with breeding pigs in the EU, 2008, Part A: Salmonella prevalence estimates. EFSA Journal 2009; 7: 1377. doi: 10.2903/j.efsa.2009.1377.

30. Funk J, Davies PR, Nichols MA. The effect of sample weight on detection of Salmonella enterica in swine feces. Journal of Veterinary Diagnostic Investigation 2000; 12: 412-418.

31. Pires AF, Funk JA, Bolin CA. Longitudinal study of Salmonella shedding in naturally infected finishing pigs. Epidemiology and Infection 2013; 141: 19281936. doi: $10.1017 / \mathrm{S} 0950268812002464$.

32. Sauli I, et al. Estimating the probability and level of contamination with Salmonella of feed for finishing pigs produced in Switzerland - the impact of the production pathway. International Journal of Food Microbiology 2005; 100: 289-310. doi: 10.1016/j. ijfoodmicro.2004.10.026.

33. Prohászka L, et al. The role of intestinal volatile fatty acids in the Salmonella shedding of pigs. Zentralblatt für Veterinärmedizin Reihe B 1990; 37: 570-574.

34. Van der Wolf PJ, et al. Administration of acidified drinking water to finishing pigs in order to prevent Salmonella infections. Veterinary Quarterly 2001; 23: 121-125. doi: 10.1080/01652176.2001.9695097.

35. Van Winsen RL et al. Mechanism of Salmonella reduction in fermented pig feed. Journal of the Science of Food and Agriculture 2000; 83: 342-346.

36. Wilkins W, et al. Distribution of Salmonella serovars in breeding, nursery, and grow-to-finish pigs, and risk factors for shedding in ten farrow-to-finish swine farms in Alberta and Saskatchewan. Canadian Journal of Veterinary Research 2010; 74: 81-90.

37. Visscher CF, et al. Effects of feed particle size at dietary presence of added organic acids on caecal parameters and the prevalence of Salmonella in fattening pigs on farm and at slaughter. Journal of Animal Physiology and Animal Nutrition 2009; 93: 423-430. doi: 10.1111/ j.1439-0396.2008.00821.x.

38. Missotten JAM, et al. Fermented liquid feed for pigs: an ancient technique for the future. Journal of Animal Science and Biotechnology 2015; 6: 4. Published online 20 January 2015. doi: 10.1186/2049-1891-6-4.

39. O'Connor AM, et al. Feeding management practices and feed characteristics associated with Salmonella prevalence in live and slaughtered market-weight finisher swine: a systematic review and summation of evidence from 1950 to 2005. Preventive Veterinary Medicine 2008; 87: 213-228. doi: 10.1016/j. prevetmed.2008.06.017.

40. Lo Fo Wong DMA, et al. Herd level risk factors for subclinical Salmonella infection in European finishing-pig herds. Preventive Veterinary Medicine 2004; 62: 253266. doi: 10.1016/j.prevetmed.2004.01.001.

41. García-Feliz C, et al. Herd-level risk factors for faecal shedding of Salmonella enterica in Spanish fattening pigs. Preventive Veterinary Medicine 2009; 91: 130-136. doi: 10.1016/j.prevetmed.2009.05.011.
42. Gotter V, et al. Main risk factors for Salmonellainfections in pigs in north-western Germany. Preventive Veterinary Medicine 2012; 106: 301-307. doi: 10.1016/j. prevetmed.2012.03.016.

43. Fosse J, Seegers H, Magras C. Prevalence and risk factors for bacterial food-borne zoonotic hazards in slaughter pigs: a review. Zoonoses and Public Health 2009; 56: 29-54. doi: 10.1111/j.1863-2378.2008.01185.x.

44. Marin C, Hernandiz A, Lainez M. Biofilm development capacity of Salmonella strains isolated in poultry risk factors and their resistance against disinfectants. Poultry Science 2009; 88: 424 431. doi: 10.3382/ps.2008-00241.

45. Rajić A, et al. Salmonella infections in ninety Alberta swine finishing farms: serological prevalence, correlation between culture and serology, and risk factors for infection. Foodborne Pathogens and Disease 2007; 4: 169-177. doi: 10.1089/fpd.2006.0073.

46. Rasschaert G, et al. Effect of farm type on within-herd Salmonella prevalence, serovar distribution, and antimicrobial resistance. Journal of Food Protection 2012; 75: 859-866. doi: 10.4315/0362-028X.JFP-11-469.

47. Nollet N, et al. Salmonella in sows: a longitudinal study in farrow-to-finish pig herds. Veterinary Research 2005; 36: 645-656. doi: 10.1051/vetres:2005022.

48. Dors A, et al. Prevalence and risk factors for Lawsonia intracellularis, Brachyspira hyodysenteriae and Salmonella spp. in finishing pigs in Polish farrow-to-finish swine herds. Polish Journal of Veterinary Sciences 2015; 18: 825-831. doi: 10.1515/pjvs-2015-0107.

49. Rostagno MH, Eicher SD, Lay DC. Jr Does preslaughter stress affect pork safety risk? In: Proceedings of the 21st International Pig Veterinary Society (IPVS) Congress, July 18-21, 2010, Vancouver, Canada. p. 176.

50. Martín-Peláez S, et al. Different feed withdrawal times before slaughter influence caecal fermentation and faecal Salmonella shedding in pigs. Veterinary Journal 2009; 182: 469-473. doi: 10.1016/j.tvj1.2008.08.002.

51. Bonardi S, et al. Detection of Salmonella enterica in pigs at slaughter and comparison with human isolates in Italy. International Journal of Food Microbiology 2016; 218: 44-50. doi: 10.1016/j.ijfoodmicro.2015.11.005.

52. Hurd HS, Gailey JK, Rostagno MH. Rapid infection in market swine occurs following exposure to a Salmonella contaminated environment. American Journal of Veterinary Research 2001; 62: 1194-1197.

53. Dickson JS, Hurd HS, Rostagno MH. Salmonella in the pork production chain. National Pork Board /American Meat Science Association Fact Sheet. Published online: 11 December 2015.

54. Anon. Regulation (EC) No 1099/2009 of the Council of 24 September 2009 on the protection of animals at the time of killing. Official Journal of the European Union 2009; L 303: 1-30.

55. De Busser EV, et al. Salmonella control in live pigs and at slaughter. Veterinary Journal 2013; 196: 20-27. doi: 10.1016/j.tvj1.2013.01.002.

56. Schütte A, et al. Effect of different kinds of showering in lairage on physiological and meat quality parameters, taking climate circumstances into account. 
Landbauforschung Völkenrode Sonderheft 1996; 166: 181-201.

57. Rossel R, Jouffe L, Belceil P-A. Analysis of factors associated with Salmonella isolation on pork carcass using Bayesian networks. Journées de la Recherche Porcine 2009; 41: 43-48.

58. Bonardi S, et al. Influence of pig skin in Salmonella contamination of pig carcasses and cutting lines in an Italian slaughterhouse. Italian Journal of Food Safety 2016; 5: 65-68. doi: 10.4081/ijfs.2016.5654.

59. Gomes-Neves E, et al. Salmonella cross-contamination in swine abattoirs in Portugal: carcasses, meat and meat handlers. International Journal of Food Microbiology 2012; 157: 82-87. doi: 10.1016/j. ijfoodmicro.2012.04.015.

60. Marier EA, et al. Abattoir based survey of Salmonella in finishing pigs in the United Kingdom 2006-2007. Preventive Veterinary Medicine 2014; 117: 542-553. doi: 10.1016/j.prevetmed.2014.09.004.

61. Vieira-Pinto M, Temudo P, Martins C. Occurrence of Salmonella in the ileum, ileocolic lymph nodes, tonsils, mandibular lymph nodes and carcasses of pigs slaughtered for consumption. Journal of Veterinary Medicine. B, Infectious Diseases and Veterinary Public Health 2005; 52: 476-481. doi: 10.1111/ j.1439-0450.2005.00892.x.

62. De Busser EV, et al. Detection and characterization of Salmonella in lairage, on pig carcasses and intestines in five slaughterhouses. International Journal of Food Microbiology 2011; 145: 279-286. doi: 10.1016/j. ijfoodmicro.2011.01.009.

63. Powell LF, et al. A prevalence study of Salmonella spp., Yersinia spp., Toxoplasma gondii and porcine reproductive and respiratory syndrome virus in UK pigs at slaughter. Epidemiology and Infection 2016; 144: 15381549. doi: 10.1017/S0950268815002794.

64. Bonardi S, et al. Prevalence, characterization and antimicrobial susceptibility of Salmonella enterica and Yersinia enterocolitica in pigs at slaughter in Italy. International Journal of Food Microbiology 2013; 163: 248-257. doi: 10.1016/j.ijfoodmicro.2015.11.005.

65. Smid JH, et al. Quantifying the sources of Salmonella on dressed carcasses of pigs based on serovar distribution. Meat Science 2014; 96: 1425-1431. doi: 10.1016/ j.meatsci.2013.12.002.

66. Argüello $\mathbf{H}$, et al. Role of slaughtering in Salmonella spreading and control in pork production. Journal of Food Protection 2013; 76: 899-911. doi: 10.4315/ 0362-028X. JFP-12-404.

67. Duggan SJ, et al. Tracking the Salmonella status of pigs and pork from lairage through the slaughter process in the Republic of Ireland. Journal of Food Protection 2010; 73: 2148-2160.

68. van Hoek AH, et al. A quantitative approach towards a better understanding of the dynamics of Salmonella spp. in a pork slaughter-line. International Journal of Food Microbiology 2012; 153: 45-52. doi: 10.1016/j. ijfoodmicro.2012.04.015.

69. Botteldoorn N, et al. Phenotypic and molecular typing of Salmonella strains reveals different contamination sources in two commercial pig slaughterhouses. Applied and Environmental Microbiology 2004; 70: 5305-5314. doi: 10.1128/AEM.70.9.5305-5314.2004.

70. Bolton DJ, Ivory C, McDowell D. A study of Salmonella in pigs from birth to carcass: serotypes, genotypes, antibiotic resistance and virulence profiles. International Journal of Food Microbiology 2013; 160: 298-303. doi: 10.1016/j.ijfoodmicro.2012.11.001.

71. Anon. Regulation (EC) 2015/1474 of 27 August concerning the use of recycled hot water to remove microbiological surface contamination from carcasses. Official Journal of the European Union 2015; L 225: 7-9.

72. Gebreyes WA, et al. Salmonella enterica serovars from pigs on farms and after slaughter and validity of using bacteriologic data to define herd Salmonella status. Journal of Food Protection 2004; 67: 691-697.

73. European Food Safety Authority, European Centre for Disease Prevention and Control. The European Union summary report on trends of zoonoses, zoonotic agents and food-borne outbreaks in 2013. EFSA Journal 2015; 13: 3991. doi: 10.2903/j.efsa.2015.3991.

74. Hauser E, et al. Pork contaminated with Salmonella enterica serovar 4,[5],12:i:-, an emerging health risk for humans. Applied and Environmental Microbiology 2010; 76: 4601-4610. doi: 10.1128/AEM.02991-09.

75. Lucarelli C, et al. Evidence for a second genomic island conferring multidrug resistance in a clonal group of strains of Salmonella enterica serovar Typhimurium and its monophasic variant circulating in Italy, Denmark, and the United Kingdom. Journal of Clinical Microbiology 2010; 48: 2103-2109. doi: 10.1128/JCM.01371-09.

76. Anon. Regulation (EC) No 2073/2005 of the Commission of 15 November 2005 on microbiological criteria for foodstuff. Official Journal of the European Union 2005; L 338: 1-26.

77. Anon. Regulation (EU) of the Commission No 217/2014 of 7 March 2014 amending Regulation (EC) No 2073/ 2005 as regards Salmonella in pig carcases. Official Journal of the European Union 2014; L 69: 93-94.

78. De Knegt LV, Pires SM, Hald T. Attributing foodborne salmonellosis in humans to animal reservoirs in the European Union using a multi-country stochastic model. Epidemiology and Infection 2015; 143: 1175 1186. doi: 10.1017/S0950268814001903.

79. Cohen JL, Bartlett JA, Corey R. Extra-intestinal manifestations of Salmonella infections. Medicine (Baltimore) 1987; 66: 349-388.

80. Paranthaman K, et al. Emergence of a multidrug-resistant (ASSuTTm) strain of Salmonella enterica serovar Typhimurium DT120 in England in 2011 and the use of multiple-locus variable-number tandem-repeat analysis supporting outbreak investigations. Foodborne Pathogens and Disease 2013; 10: 850-855. doi: 10.1089/ fpd.2013.1513.

81. Lettini AA, et al. Characterization of an unusual Salmonella phage type DT7a and report of a foodborne outbreak of salmonellosis. International Journal of Food Microbiology 2014; 189: 11-17. doi: 10.1016/j. ijfoodmicro.2014.07.021. 
82. Barco L, et al. Molecular characterization of Salmonella enterica serovar 4,[5],12:i:- DT193 ASSuT strains from two outbreaks in Italy. Foodborne Pathogens and Disease 2014; 11: 138-144. doi: 10.1089/fpd.2013.1626.

83. Leekitcharoenphon $\mathbf{P}$, et al. Evaluation of whole genome sequencing for outbreak detection of Salmonella enterica. PLoS ONE 2014; 9: e87991. Published on line: 4 February 2014. doi.org/10.1371/journal.pone.0087991.

84. Kérouanton A, et al. Genetic diversity and antimicrobial resistance profiles of Salmonella enterica serotype Derby isolated from pigs, pork, and humans in France. Foodborne Pathogens and Disease 2013; 10: 977-984. doi: 10.1089/fpd.2013.1537.

85. Kérouanton A, et al. First complete genome sequence of a Salmonella enterica subsp. enterica serovar Derby strain associated with pork in France. Genome Announcements 2015; 3: e00853-15. Published online: 30 July 2015. doi: 10.1128/genomeA.00853-15.

86. Gallati C, et al. Characterization of Salmonella enterica subsp. enterica serovar 4,[5],12:i:- clones isolated from human and other sources in Switzerland between 2007 and 2011. Foodborne Pathogens and Disease 2013; 10: 549-554. doi: 10.1089/fpd.2012.1407.

87. Sandt CH, et al. A comparison of non-typhoidal Salmonella from humans and food animals using pulsed-field gel electrophoresis and antimicrobial susceptibility patterns. PLoS ONE 2013; 8: e77836. Published online: 30 October 2013. doi: 10.1371/journal.pone.0077836.

88. Arnedo-Pena A, et al. An outbreak of monophasic and biphasic Salmonella Typhimurium, and Salmonella Derby associated with the consumption of dried pork sausage in Castellon (Spain). Enfermedades Infecciosas Microbiología Clínica 2016; 34: 544-550. doi: 10.1016/ j.eimc.2015.11.016.

89. Wójcik OP, et al. Salmonella Typhimurium outbreak associated with smoked pork tenderloin in Denmark, January to March 2011. Scandinavian Journal of Infectious Diseases 2012; 44: 903-908. doi: 10.3109/ 00365548.2012 .693196$.

90. Kuhn KG, et al. A long-lasting outbreak of Salmonella Typhimurium U323 associated with several pork products, Denmark, 2010. Epidemiology and Infection 2013; 141: 260-268. doi: 10.1017/S0950268812000702.

91. Kuhn K, et al. An outbreak of Salmonella Typhimurium traced back to salami, Denmark, April to June 2010. Euro Surveillance 2011; 16. Published online: 12 May 2011.

92. Luzzi I, et al. An Easter outbreak of Salmonella Typhimurium DT 104A associated with traditional pork salami in Italy. Euro Surveillance 2007; 12: 149-152.

93. Alt K, et al. Outbreak of uncommon $\mathrm{O} 4$ nonagglutinating Salmonella typhimurium linked to minced pork, Saxony-Anhalt, Germany, January to April 2013. PLoS ONE 2015; 10: e0128349. Published online: 1 June 2015. doi: 10.1371/journal.pone.0128349.

94. Frank C, et al. Catering risky food to those at-risk: Salmonella Derby outbreak among the elderly in Berlin, December 2013/January 2014. In: Proceedings of the European Scientific Conference on Applied Infectious Disease, Stockholm; 5-7 November 2014.
95. European Food Safety Authority. Scientific opinion of the Panel on Biological Hazards on a request from the Health and Consumer Protection, Directorate General, European Commission on Microbiological Risk Assessment in feeding stuffs for food producing animals. EFSA Journal 2008; 720: 1-84. doi: 10.2903/ j.efsa.2008.720.

96. Mueller-Doblies D, Speed K, Davies RH. A retrospective analysis of Salmonella serovars isolated from pigs in Great Britain between 1994 and 2010. Preventive Veterinary Medicine 2013; 110: 447-455. doi: 10.1016/ j.prevetmed.2013.02.023.

97. Gomes-Neves E, et al. Clinically relevant multidrug resistant Salmonella enterica in swine and meat handlers at the abattoir. Veterinary Microbiology 2014; 168: 229 233. doi: 10.1016/j.vetmic.2013.10.017.

98. Korsak N, et al. Salmonella contamination of pigs and pork in an integrated pig production system. Journal of Food Protection 2003; 66: 1126-1133.

99. Pornsukarom S, et al. Comparative phenotypic and genotypic analyses of Salmonella Rissen that originated from food animals in Thailand and United States. Zoonoses and Public Health 2015; 62: 151-158. doi: 10.1111/zph.12144.

100. Antunes P, et al. Leakage of emerging clinically relevant multidrug-resistant Salmonella clones from pig farms. Journal of Antimicrobial Chemotherapy 2011; 66: 2028-2032. doi: 10.1093/jac/dkr228.

101. Borch E, Nesbakken T, Christensen H. Hazard identification in swine slaughter with respect to foodborne bacteria. International Journal of Food Microbiology 1996; 30: 9-25.

102. Baptista FM, Dahl J, Nielsen LR. Factors influencing Salmonella carcass prevalence in Danish pig abattoirs. Preventive Veterinary Medicine 2010; 95: 231-238. doi: 10.1016/j.prevetmed.2010.04.007.

103. Anon. Regulation (EC) No 2160/2003 of the European Parliament and of the Council of 17 November 2003 on the control of Salmonella and other specified foodborne zoonotic agents. Official Journal of the European Union 2003; L 325: 1-15.

104. Bollaerts K, et al. Evaluation of scenarios for reducing human salmonellosis through household consumption of fresh minced pork meat. Risk Analysis 2010; 30: 853-865. doi: 10.1111/j.1539-6924.2010.01368.x.

105. European Food Safety Authority. Scientific opinion on a quantitative microbiological risk assessment of Salmonella in slaughter and breeder pigs. EFSA Journal 2010; 8: 1547. doi: 10.2903/j.efsa.2010.1547.

106. Merle R, et al. Serological Salmonella monitoring in German pig herds: results of the years 2003-2008. Preventive Veterinary Medicine 2011; 99: 229-233. doi: 10.1016/j.prevetmed.2011.02.007.

107. Alban L, Stege H, Dahl J. The new classification system for slaughter-pig herds in the Danish Salmonella surveillance-and-control program. Preventive Veterinary Medicine 2002; 53: 133-146.

108. Blaha T. Bisherige Erkenntnisse aus dem QS Salmonellenmonitoring-und-reduzierungsprogramm. Deutsche Tierarztliche Wochenschrift 2004; 111: 324-326. 